INTERVENTIONAL CARDIOLOGY AND SURGERY

\title{
Isolated left main coronary artery stenosis: long term follow up in 106 patients after surgery
}

\author{
F Revault d'Allonnes, H Corbineau, H Le Breton, C Leclercq, A Leguerrier, C Daubert
}

Heart 2002;87:544-548

See end of article for authors' affiliations

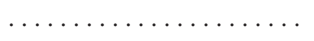

Correspondence to: Dr Florence Revault d'Allones, Department of Cardiology, Rennes University Hospital, 2 rue Henri Le Guilloux, 35033

Rennes Cedex 09, France; jean-claude.daubert @CHU-Rennes.fr

Accepted 6 March 2002

\begin{abstract}
Objective: To analyse the long term prognosis in patients with isolated stenoses of the left main coronary artery (LMCA) following surgical revascularisation.

Patients: 106 patients (71 men and 35 women, mean age 61 years) were operated on between 1982 and 1998. Before surgery, 103 patients presented with angina pectoris and only 10 had a history of myocardial infarction. Their mean left ventricular ejection fraction was $62 \%$. Stenoses were localised on the LMCA ostium in 19 patients, a subgroup characterised by a high proportion of women (68\%). Three patients presented with chronic LMCA occlusion. Forty six patients were operated on as an emergency. The mean (SD) number of grafts per patient was $2.0(0.5)$, and only one patient had no left anterior descending (LAD) coronary artery bypass. Bypass of the LAD using the internal thoracic artery was performed in 88 cases.

Results: Early postoperative mortality was $4.7 \%$ and the five year survival was $86.8 \%$. Late mortality occurred in nine cases, and in three of these it was linked to a coronary condition. Of the 92 long term survivors, $81.5 \%$ were totally symptom-free and $77 \%$ of those of working age were able to resume work. The postoperative outcome of patients with isolated ostial LMCA stenosis did not differ significantly from that of the other patients.

Conclusions: The postoperative prognosis of isolated LMCA stenosis appears good in terms of mortality and symptoms.
\end{abstract}

$\mathrm{S}$ nce James Herrick's original description of a left main coronary artery (LMCA) stenosis in 1912, ${ }^{1}$ the natural outcome of this type of lesion has been thought to be poor. A study by Conley and colleagues, ${ }^{2}$ conducted between 1960 and 1977, analysed the outcome of 163 medically treated cases of LMCA stenosis. The survival rate was $79 \%$ after one year and $50 \%$ after three years. Dacosta and associates, in a review of several studies, ${ }^{3}$ reported a survival rate of around 50\% after three years, with a $19 \%$ annual mortality rate. Both rates were very similar to those noted in non-operated triple vessel disease. Only patients with non-bypassable vessels, a left ventricular ejection fraction of less than $20 \%$, associated incurable disease, or refusing surgery would be considered ineligible for surgical treatment. It is clear, however, that advances in surgical myocardial revascularisation techniques have had an important impact on prognosis. While various studies have focused on the outcome of LMCA stenoses following surgery, ${ }^{45}$ few have investigated the long term outcome ${ }^{67}$ and none has specifically involved the subpopulation of patients with isolated LMCA stenosis. Our aim in this study was to analyse retrospectively the long term outcome after surgery in patients presenting with isolated LMCA stenoses.

\section{METHODS}

\section{Patient selection}

Among the 7783 patients receiving coronary artery bypass surgery in the thoracic and cardiovascular surgery department of our hospital between 1982 and 1998, all those who met the following criteria were included in the study:

- the presence of LMCA stenosis, as defined by a reduction of the arterial lumen by more than 50\%;

- LMCA stenosis not accompanied by any significant stenosis of the other coronary arteries;

- myocardial revascularisation done without any associated procedures ( such as valve replacement, aneurysm resection, ascending aorta replacement, and so on).

\section{Data analysis}

The patients' characteristics were determined by analysis of computerised databases and the medical records. The data collected included age, sex, and the presence of risk factors for atherosclerosis. The symptoms leading to preoperative coronary arteriography and preoperative myocardial infarction were analysed.

The left ventricular ejection fraction was computed by angiography (Stanford method, $30^{\circ}$ right anterior view). Selective coronary arteriography was undertaken using the Judkins femoral or brachial technique, with a minimum of three views (right anterior oblique, left anterior, and left lateral).

Various surgical aspects of the database were also analysed. These included whether the procedure was carried out as an emergency (that is, when patients were admitted to hospital while awaiting surgery and were operated on within three days after the decision to operate was made), the number and types of grafts, extracorporeal circulation and aortic clamping times, and the causes of early postoperative deaths.

\section{Progression survey}

Long term follow up was achieved by sending questionnaires to the patients, their physicians, and their cardiologists. If there was no response to the questionnaires or if they contained inconsistencies, further inquiries were made by telephone. Records of any past hospital admissions were evaluated. Finally, in the absence of any response to our inquiries, the possibility that the patient had died was checked with the death registry administration.

\section{Statistical analysis}

Statistical processing was performed with the Statview software (version F4,5). In the initial univariate analyses we used Pearson's $\chi^{2}$ test or Fisher's exact test for qualitative data and Student's $t$ test or analysis of variance for quantitative data. As a second step, a survival analysis was done (using 
Table 1 Preoperative and peroperative characteristics of the patients

\begin{tabular}{|c|c|c|c|c|}
\hline & $\begin{array}{l}\text { All patients } \\
(n=106)\end{array}$ & $\begin{array}{l}\text { Ostial stenosis } \\
(\mathrm{n}=19)\end{array}$ & $\begin{array}{l}\text { Non-ostial } \\
\text { stenosis }(n=87)\end{array}$ & $\begin{array}{l}\mathrm{p} \text { Value: ostial } v \\
\text { non-ostial }\end{array}$ \\
\hline Death & 14 & 0 & 14 & NS \\
\hline Perioperative & 5 & & 5 & \\
\hline Postoperative & 9 (3 cardiac) & & & \\
\hline Coronary events & 16 & 3 & 13 & NS \\
\hline Female & 35 & 13 & 22 & 0.0007 \\
\hline Age (years) & $61(10)$ & $60.3(10.7)$ & $61(10.3)$ & NS \\
\hline Hypertension & 43 & 8 & 35 & NS \\
\hline Smoking & 39 & 4 & 35 & NS \\
\hline Diabetes mellitus & 7 & 3 & 4 & NS \\
\hline Hypercholesterolaemia & 54 & 12 & 42 & NS \\
\hline Obesity & 20 & 2 & 18 & NS \\
\hline Number of risk factors & & $1.4(0.8)$ & $1.5(1.1)$ & NS \\
\hline LV ejection fraction (\%) & $62(13)$ & $63(18)$ & $62(12)$ & NS \\
\hline Preoperative symptoms & & & & NS \\
\hline $\begin{array}{l}\text { Angina pectoris (exercise } \\
\text { induced) }\end{array}$ & 49 & 14 & 35 & \\
\hline Mixed or unstable angina & 54 & 9 & 45 & \\
\hline Myocardial infarction & 10 & 1 & 9 & \\
\hline Dyspnoea & 3 & 0 & 3 & \\
\hline LMCA stenosis percentage & & & & NS \\
\hline $100 \%$ & 3 & 0 & 3 & \\
\hline$>70 \%$ & 85 & 18 & 67 & \\
\hline $50-70 \%$ & 18 & 1 & 17 & \\
\hline Emergency & 46 & 6 & 40 & NS \\
\hline$L A D$ venous grafts & 17 & 1 & 16 & NS \\
\hline ECC time (min) & $70(29)$ & $70(24)$ & $70(30)$ & NS \\
\hline Aortic clamping time (min) & 46 (14) & $46(16)$ & 43 (14) & NS \\
\hline
\end{tabular}

Kaplan-Meier's actuarial curve method) with the log rank univariate test, followed by Cox's proportional rate multivariate model. The significance threshold was set at $\mathrm{p}<0.05$ for all these data. Data are given as mean (SD).

\section{RESULTS}

\section{Population characteristics}

The patient population (table 1) consisted of 35 women and 71 men (total 106), mean age, 61 (10) years (range 37-79 years). Cardiovascular risk factors other than age were present in 85 patients. Angina pectoris was the presenting symptom in 103 patients (exercise induced angina in $46.2 \%$, mixed in $42.5 \%$, and unstable angina leading to emergency hospital admission in $8.5 \%$ ). Only three patients presented with isolated exercise induced dyspnoea. Ten patients $(9.4 \%)$ had a history of preoperative myocardial infarction.

The mean left ventricular ejection fraction measured preoperatively was $62(13) \%$. The degree of LMCA stenosis was quantified in all patients by preoperative coronary arteriography $(50-70 \%$ in 18 patients; $>70 \%$ in 85 ; chronic occlusion in three). We were able to define precise lesion topography in 97 patients (distal in 52; median in 13; proximal in 13; and ostial in 19).

Forty six operations were performed as emergencies. The mean number of grafts per patient was $2.0(0.5)$. Seventeen patients received only venous grafts ( 14 of these were before 1990). The left anterior descending coronary artery was bypassed in 105 patients, using the internal thoracic artery in 88 cases and a venous graft in 17. In most cases, one or several other arteries were bypassed, essentially using saphenous vein graft (diagonal branch in 7, circumflex branch in 34, marginal branch in 61). Extracorporeal circulation time and aortic clamping time were 70 (29) minutes and 46 (14) minutes, respectively.

\section{Follow up}

The mean follow up duration in November 1998 was 57.8 (42.4) months. Data were obtained on the outcome of all surviving patients. All 92 survivors answered the questionnaire.

\section{Mortality}

The overall mortality (fig l) at the end of follow up was 13.2\% (14 deaths). Early postoperative mortality before hospital discharge was $4.7 \%$. Of these five deceased patients (four men and one woman), the first three died on the day of surgery from refractory low cardiac output. The two remaining patients died, respectively, on the third postoperative day from mesenteric infarction, and on the fourth day after a myocardial infarct secondary to acute thrombosis of the circumflex graft, confirmed by necropsy in both cases.

Late mortality (4.6 (3.4) years after surgery) was $8.5 \%$. Three patients died of cardiac causes (all men) and six from other causes (cancer, renal failure, and a car crash; four men and two women).

\section{Functional outcome}

At the time when the questionnaires were dispatched, 17 (18.5\%) of the 92 surviving patients were complaining of recurrent angina, which began at a mean of 3.3 (2.8) years

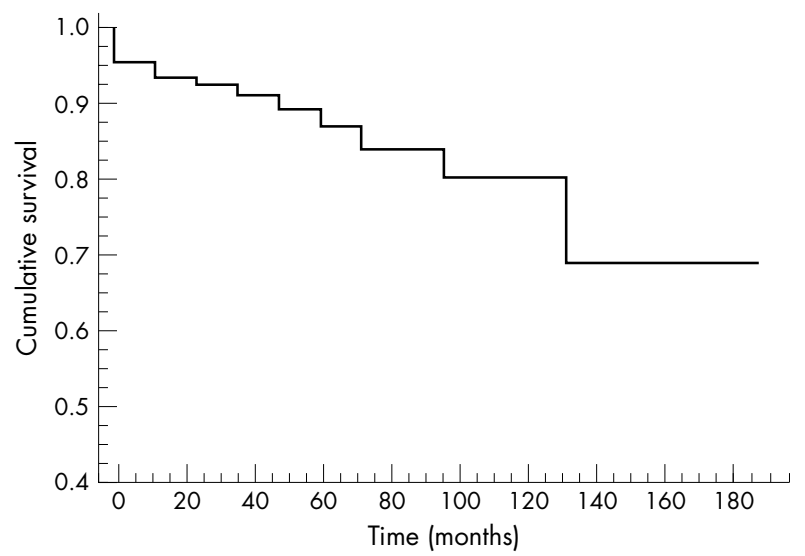

Figure 1 Actuarial survival curve. 


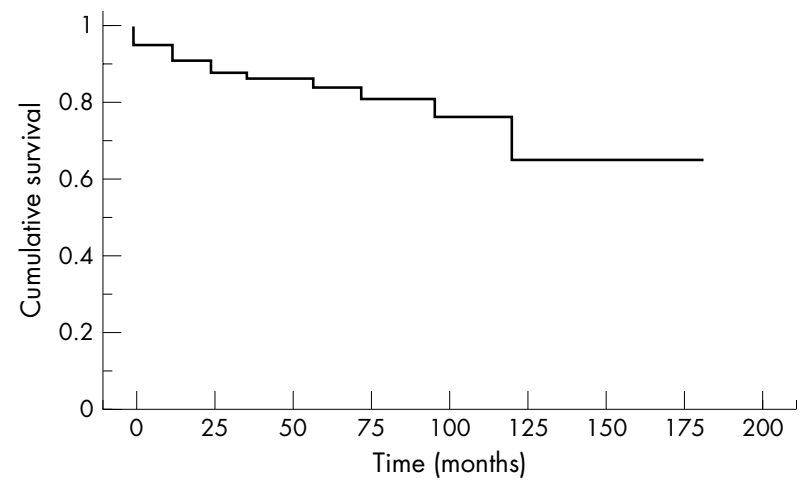

Figure 2 Actuarial survival curve without coronary events.

after surgery. Three patients who had been symptomatic during follow up were no longer so at the end of the study. Two patients suffered from lateral infarcts in the course of follow up. Of the 26 patients of working age, $76.9 \%$ had resumed their jobs and $23.1 \%$ were either in premature retirement or were incapacitated.

All patients received anti-ischaemic drug treatment $(\beta$ blockers in $77.2 \%$ of cases) and 91 of the 92 patients were on antiplatelet drugs (aspirin or ticlopidine, $\mathrm{n}=77$ ) or an oral anticoagulant (warfarin, $\mathrm{n}=14$ ) .

As assessed by their cardiologists, in 44 patients the mean left ventricular ejection fraction was $58(8) \%$. Fifty nine patients underwent exercise stress tests, of which 51 (86.4\%) were negative, both clinically and on ECG criteria.

Sixteen patients (17.4\% of the survivors) underwent follow up coronary angiography (because of functional symptoms in 12 cases and a positive exercise test in two, and as a routine procedure prescribed by their cardiologists in the remaining two). Results were considered fully satisfactory in six of these patients, two were reoperated on, five had percutaneous angioplasty (of the LMCA in three and of the bypass in two), and three patients remained on medical treatment.

\section{Predictors of coronary events}

Coronary events were defined as a death of cardiac origin ( $\mathrm{n}=8$; five early and three late), the occurrence of myocardial infarction during follow up $(\mathrm{n}=2)$, or the need for a new myocardial revascularisation procedure in the course of follow up $(\mathrm{n}=7$, including five percutaneous coronary angioplasties (PTCA) and two reoperations). One of the PTCAs was done in a patient who had suffered a myocardial infarct. Thus the total number of coronary events was 16 . The event-free follow up curve is shown in fig 2 .

In the univariate analysis (tables 2 and 3), three factors appeared to be associated with the occurrence of coronary events: extracorporeal circulation time $(82 v 68$ mins, $\mathrm{p}<0.05$ ), aortic clamping time ( $51 v 43$ mins, $\mathrm{p}<0.05$ ), and the presence of preoperative obesity, defined by a body mass index of more than $30 \mathrm{~kg} / \mathrm{m}^{2}(37.5 \% v 14.3 \%, \mathrm{p}<0.05)$. In the survival analysis using the log rank test, extracorporeal circulation times of more than 90 minutes (odds ratio (OR) 3.993, 95\% confidence interval (CI) 1.304 to 12.24) and aortic clamping times of more than 44 minutes (OR 3.001, 95\% CI 1.260 to 7.144 ) were found to increase the risk of coronary event occurrence significantly. In the multivariate analysis, a clamping time of more than 44 minutes appeared to be predictive of later coronary events $(p=0.01)$, while an extracorporeal circulation time of more than 90 minutes was very close to being significant $(\mathrm{p}=0.06)$.

\section{Ostial stenoses}

Nineteen patients (17.9\%) presented with isolated ostial stenosis of the LMCA. This subpopulation was composed of 13
Table 2 Preoperative and peroperative data in patients with or without coronary events (non-cardiac deaths excluded)

\begin{tabular}{|c|c|c|c|}
\hline & $\begin{array}{l}\text { Coronary } \\
\text { events }(n=16)\end{array}$ & $\begin{array}{l}\text { No coronary } \\
\text { events } \\
(n=84)\end{array}$ & $\mathrm{p}$ Value \\
\hline Female & 4 & 29 & NS \\
\hline Age (years) & $56.1(11)$ & $61 .(69.9)$ & NS \\
\hline Hypertension & 7 & 32 & NS \\
\hline Smoking & 7 & 30 & NS \\
\hline Diabetes mellitus & 1 & 6 & NS \\
\hline Hypercholesterolaemia & 11 & 42 & NS \\
\hline Obesity & 6 & 12 & 0.011 \\
\hline Number of risk factors & $1.9(1.2)$ & $1.4(1.0)$ & NS \\
\hline LV ejection fraction (\%) & $61(12)$ & 62 (13) & NS \\
\hline Preoperative symptoms & & & NS \\
\hline $\begin{array}{l}\text { Angina pectoris } \\
\text { (exercise induced) }\end{array}$ & 5 & 42 & \\
\hline $\begin{array}{l}\text { Mixed or unstable } \\
\text { angina }\end{array}$ & 9 & 33 & \\
\hline Myocardial infarction & 2 & 7 & \\
\hline Dyspnoea & 0 & 3 & \\
\hline \multicolumn{2}{|l|}{ Percentage of $L M C A$ stenosis } & & NS \\
\hline $100 \%$ & 1 & 2 & \\
\hline$>70 \%$ & 17 & 68 & \\
\hline $50-70 \%$ & 1 & 17 & \\
\hline LMCA stenosis location & & & NS \\
\hline Distal & 8 & 44 & \\
\hline Medial & 3 & 10 & \\
\hline Proximal & 3 & 10 & \\
\hline Emergency & 6 & 36 & NS \\
\hline$L A D$ venous grafts & 2 & 12 & NS \\
\hline ECC time (min) & $82(51)$ & $68(22)$ & 0.008 \\
\hline Aortic clamping time (min) & $51(20)$ & 43 (13) & 0.007 \\
\hline
\end{tabular}

Values are $\mathrm{n}$ or mean (SD).

ECC, extracorporeal circulation; LAD, left anterior descending coronary artery; LMCA, left main coronary artery; LV, left ventricular.

Table 3 Comparison of postoperative data in long term survivors with or without coronary events (all deaths excluded)

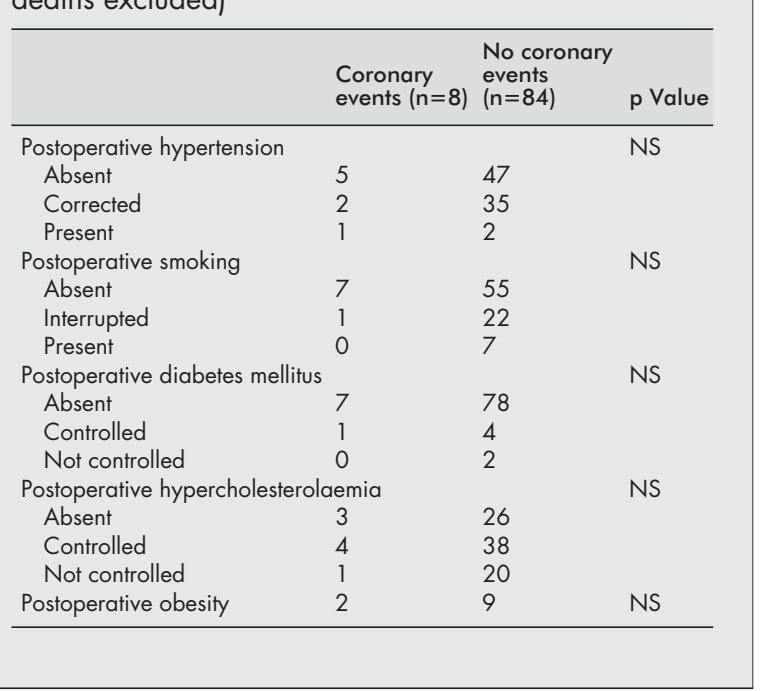

women $(68 \%)$ and six men. Among these 19 patients, one woman had Takayasu's disease, which was known about before the diagnosis of coronary artery disease. No specific aetiology could be established in the other 18 patients. In the subgroup of patients with isolated LMCA ostial stenosis, 11 underwent direct angioplasty of the left main trunk, but the result was considered satisfactory in only nine. Eight angioplasties were associated with a left anterior descending coronary artery single bypass using the internal thoracic artery. The only patient who had an isolated angioplasty 
needed reoperation three months later (standard dual bypass to the left anterior descending and circumflex coronary arteries).

Comparison between the subpopulation of 19 patients with isolated LMCA stenosis and the remainder of the population (table 1) showed that the only significant difference between the two populations was a greater proportion of women in the ostial stenosis group $(68.4 \% v 25.9 \%, p=0.0007)$. It is nevertheless worth noting that, while no deaths occurred in that subgroup, survival without coronary events $(84.2 \%$ in the ostial stenosis group $v 85 \%$ in the rest of the population) did not differ significantly between the two groups.

Finally, there was no statistical difference in event-free survival between the nine patients who underwent truncus angioplasty (event-free in five) and the other 10 patients who had isolated bypasses (event-free in eight).

\section{DISCUSSION \\ Prevalence of isolated LMCA stenoses}

The 106 patients in this study were selected from a population of 1727 patients who had been operated on for LMCA stenosis. This amounted to $22.9 \%$ of all the coronary patients who had had a revascularisation procedure in our centre over a 16 year period. This proportion appears high in comparison with the low frequency of LMCA stenoses generally reported (between $0.7-12.6 \%$ ). ${ }^{2}$ The difference lay in the recruitment of the patients. Published series most often relate the number of LMCA stenoses to the number of coronary angiographies performed over the same period, whereas we analysed a surgical database. Certain series were also based on surgical recruitment, with an apparently larger number of LMCA stenoses, although in those studies the investigators did not specify the total number of patients operated on for coronary disease during the same period. ${ }^{8-10}$

The ratio between isolated LMCA stenoses and the overall number of LMCA stenoses was $5.9 \%$ in our study. That rate is comparable with those found in other large series. ${ }^{56}$

\section{Mortality}

Early postoperative mortality was $4.7 \%$ in our study. This rate is consistent with several series of LMCA stenoses (isolated or not), and there is a trend towards a reduction in early mortality in the most recent studies. ${ }^{4} 58$

Overall mortality at the end of our study was $13.2 \%$ and the actuarial five year survival rate was $88 \%$. The latter figure is consistent with several reported series of non-isolated LMCA stenoses, where 4-5 year survival rates have ranged from $79-88 \% .{ }^{5810}$ In Rolle's series, ${ }^{5}$ the 18 late deaths (two thirds of which were from cardiac causes) occurred after 2.4 (2.2) years, while in our series the nine late deaths (only one third of which were cardiac) occurred 4.6 (3.4) years after surgery. Our patients therefore survived longer and their deaths tended to be non-cardiac and unrelated to their coronary condition.

In Rolle's study, ${ }^{11}$ an extracorporeal circulation time longer than 140 minutes was a factor in early mortality. In our study, extracorporeal circulation time correlated with coronary event occurrence. This is consistent with Rolle's data.

\section{Functional results}

Of the 92 surviving patients in the present series, $81.5 \%$ were free of symptoms at the end of the follow up period. Eighty four patients $(79.2 \%)$ were considered to be free of coronary events. McConahay and colleagues described the outcome of 146 patients operated on for LMCA stenoses (including only six isolated stenoses) after a mean follow up period of 18.1 months. ${ }^{9}$ Their population was younger and more predominantly male than ours. In $40 \%$ of their cases the left ventricular ejection fraction was below 50\% (compared with only $13 \%$ of our cases), and there was more often a history of myocardial infarction in McConahay's series. Despite these population differences and a shorter follow up in McConahay's study, the functional results were rather similar: $77 \%$ of survivors were asymptomatic, $74.1 \%$ of exercise tests were negative, and $48.6 \%$ of coronary arteriographies (performed on average 12.1 months after surgery) were satisfactory.

Carrie and colleagues analysed the outcome of 112 patients operated on for LMCA stenosis, with an average follow up of 18 months (range 10-32 months). ${ }^{12}$ That population was closer to ours in terms of age and left ventricular functionalthough there were more men-and $72 \%$ of the patients had unstable angina before surgery. Four patients presented with myocardial infarction during follow up $(3.5 \%, v 1.9 \%$ in our study), $93 \%$ of the patients claimed to be improved (although in reality only $89 \%$ where really symptom-free), and $79.3 \%$ of the 29 exercise tests were negative. That study focused on the return to work of 30 patients of working age (26 patients in our study): $70 \%$ had resumed work ( $76.9 \%$ in our study) and $30 \%$ took early retirement ( $23.1 \%$ in our study).

\section{Isolated LMCA ostial stenoses}

Our study population included 19 isolated LMCA ostial stenoses $(17.9 \%$ of the overall LMCA stenosis population operated on in our centre). This type of coronary lesion is considered quite rare. ${ }^{13}$ The female to male ratio in these 19 cases was 2.2. Their mean age of 60.3 (10.7) years was comparable to that of the 87 patients without ostial stenosis (61 (10.3) years), although the 13 women in the ostial stenosis group were somewhat younger (57.4 (9.2) years; NS). These data are consistent with other series reporting a high prevalence of younger women with isolated ostial stenoses. ${ }^{14}{ }^{15}$

While one patient had Takayasu' disease, there was no specific aetiology in the others. We assume that they were ostial lesions of atheromatous origin because the population had the same cardiovascular risk factors as the 87 patients without ostial stenosis (table 1). These data do not contradict other published results showing that ostial stenosis is often atheromatous, although women usually have fewer risk factors. ${ }^{13}$

The outcome in terms of survival was excellent as all these 19 patients were alive at the end of the follow up period. We cannot make comparisons with other published reports with respect to functional outcome, as in general the number of cases described has been small and the follow up periods short.

Five of the nine patients who underwent LMCA angioplasty were asymptomatic at the end of the follow up period, but there was no significant difference between that group and the remaining patients who underwent standard bypass surgery for isolated LMCA ostial stenosis. It was also difficult to make long term comparisons of angioplasty results with those of other published series, because in our patients the angioplasty was always associated with a single internal thoracic artery bypass on the left anterior descending coronary artery, making our angioplasty population a unique one. Nevertheless, the absence of operative and immediate postoperative mortality in those nine patients was consistent with the findings of other teams that perform this type of operation. ${ }^{1617}$

Bonacchi and colleagues reported 23 patients who underwent surgical ostial angioplasty, including 15 with LMCA stenosis. Patients underwent postoperative thallium-201 stress SPECT (single photon emission computed tomography) within a six month period, together with control coronary arteriography. The overall success rate after a follow up period of 49 months was $22 / 23 .^{18}$ That study confirms our positive results with the technique.

A further treatment for this type of lesion is "unprotected" PTCA of the LMCA. This has so far been reserved for emergency cases or in cases where there are absolute contraindications to surgery, but recently PTCA with coronary stent implantation has been considered as a possible first line 
alternative to surgery. This treatment is still under evaluation, and prospective studies are under way. Koning and colleagues reported a single case of PTCA with the fitting of a Palmaz-Schatz stent in a 58 year old patient with isolated LMCA ostial stenosis. ${ }^{19}$ The immediate outcome, functional follow up, and coronary arteriography after 24 months were all favourable. That lesion is particularly accessible to angioplasty, with a long and wide truncus. Other analyses of the short term benefits of PTCA in this situation (with or without stent implantation and with or without rotational or directional atherectomy) have been less encouraging ${ }^{20}{ }^{21}$; however, those two studies were not confined to isolated lesions and they also included more complex lesions, sometimes involving the distal LMCA bifurcation. The investigators' conclusions were that LMCA angioplasty should not be considered an alternative to surgery except in certain favourable situations (such as a preserved ejection fraction and a proximal lesion).

\section{Chronic LMCA occlusions}

Three patients in our study presented with an isolated LMCA occlusion-a condition considered to be very rare $^{3}$ (3-6\% of all LMCA lesions). The rarity may be explained by the fact that lesions of this type tend to be lethal early on (the incidence is 10 times higher in necropsy reports). Except in the most severe forms, revealed by massive myocardial infarction, ${ }^{22}$ no clinical or ECG signs were present to suggest truncus occlusion..$^{23}$ The three patients in our study presented with mixed angina, but without definite infarction or signs of acute heart failure.

The presence of extensive collaterals from a lesion-free right coronary artery and preservation of the left ventricular ejection fraction would contribute to a more favourable prognosis. $^{24}$ Only one patient in our study had poorly developed collaterals in the absence of right coronary artery stenosis. That patient presented with recurrent angina one year after surgery. Surgical revascularisation is the treatment of choice for chronic LMCA occlusions, and yields good results if performed at an early stage. ${ }^{25}{ }^{26}$ The three patients in our series were all alive at four, eight, and 10 years after surgery, respectively.

\section{Study limitations}

This was a retrospective study with all the biases inherent in that type of study. We followed up a population of patients operated on for isolated stenoses of the LMCA, without any randomisation or control group. The population was very heterogeneous and follow up methods differed, some patients having exercise tests or follow up coronary arteriography while others had only a clinical follow up.

Statistically, the study was restricted to analysing particular variables (preoperative, peroperative, or postoperative), although many other factors related to coronary disease may influence a patient's prognosis. Interpretation of the so called predictive factors identified in this study thus needs to be cautious. Nevertheless, the study extends our understanding of patients operated on for isolated LMCA stenoses, their postoperative course, and their management.

\section{Conclusions}

This retrospective study involved 106 patients with isolated LMCA stenosis. The results were encouraging in terms of long term outcome after surgical revascularisation (over a mean follow up of more than four years). Indeed, $86.8 \%$ of patients were alive and $71.7 \%$ were free of any intercurrent coronary events at the end of the follow up. These results are consistent with other published reports on the outcome of patients operated on for LMCA stenosis, whether isolated or not. A subpopulation with isolated ostial stenosis differed only with respect to the sex ratio (more common in women); outcome in terms of survival and functional ability was no different from that in the remaining patients. Surgical angioplasty did not appear to improve the prognosis of patients with ostial stenosis.

\section{Authors' affiliations}

F Revault d'Allonnes, H Le Breton, C Leclercq, C Daubert,

Department of Cardiology, Rennes University Hospital, rue Henri Le Guilloux, Rennes, France

H Corbineau, A Leguerrier, Department of Thoracic and

Cardiovascular Surgery, Rennes University Hospital

\section{REFERENCES}

1 Herrick J. Clinical features of sudden obstruction of the coronary arteries. JAMA 1912;59:2015-20.

2 Conley MJ, Ely RL, Kisslo J, et al. The prognosis spectrum of left main stenosis. Circulation 1978;57:947-52.

3 Dacosta A, Tardy B, Favre JP, et al. La pathologie du tronc coronaire gauche. Arch Mal Cœur 1994;87:1225-32.

4 Chaitman BR, Fisher LD, Bourassa MG, et al. Effects of coronary bypass surgery on survival patterns in subsets of patients with left main coronary artery disease. Am J Cardiol 1981;48:765-77.

5 Rolle F, Christidès C, Cornu E, et al. Sténoses significatives du tronc commun de l'artère coronaire gauche. Arch Mal Coeur 1994:87:899-905.

6 Campeau L, Corbara F, Crochet D, et al. Left main coronary artery stenosis. Circulation 1978;57:1111-15.

7 Caracciolo EA, Davis KB, Sopko G, et al. Comparison of surgical and medical group survival in patients with left main coronary disease: long term CASS experience. Circulation 1995:91:2325-34.

8 Lawrie GM, Morris GC, Howell JF, et al. Improved survival beyond 5 years after coronary bypass surgery in patients with left main coronary artery disease. Am J Cardiol 1979;44:612-15.

9 McConahay DR, Killen DA, McAllister BD, et al. Coronary artery bypass surgery for left main coronary artery disease. Am J Cardiol 1976;37:885-9.

10 Loop FD, Lytle BW, Cosgrove DM, et al. Atherosclerosis of the left main coronary artery: 5 years results of surgical treatment. Am J Cardiol 1979;44:195-201.

11 Rolle F, Cornu E, Lacroix $\mathrm{P}$, et al. Influence pronostique des divers paramètres opératoires dans les sténoses significatives du tronc coronaire gauche. Ann Chir 1995;49:212-17.

12 Carrie D, Derbel F, Delay $M$, et al. Caractères cliniques, angiographiques et suivi à 18 mois de 134 cas de sténoses du tronc commun de la coronaire gauche. Arch Mal Coeur 1989:82:2027-33.

13 Grollier G, Commeau P, Bertrand JH, et al. Les sténoses ostiales isolées: une forme anatomique particulière $d^{\prime}$ insuffisance coronarienne de la femme. Arch Mal Coeur 1987; 10:1479-86.

14 Hutter JA, Pasaoglu I, Williams BT. The incidence and management of coronary ostial stenosis. J Cardiovasc Surg 1985;26:581-4.

15 Stewart JT, Ward DE, Davies M, et al. Isolated coronary ostial stenosis: observations on the pathology. Eur Heart J 1987;8:917-20.

16 Jegaden O, Eker A, Durand de Gevigney G, et al. Plastie chirurgicale des troncs coronaires: une alternative aux techniques de pontage. Arch Mal Coeur 1994;87:1325-9.

17 Sullivan JA, Murphy DA. Surgical repair of stenotic ostial lesions of the left main coronary artery. J Thorac Cardiovasc Surg 1989;98:33-6.

18 Bonacchi M, Prifti E, Giunti G, et al. Mid-term outcome of surgical coronary ostial plasty: our experience. J Card Surg 1999;14:294-300.

19 Koning $\mathbf{R}$, Cribier A, Eltchaninoff $\mathrm{H}$, et al. Traitement en première intention des lésions du tronc commun de la coronaire gauche par implantation percutanée d'une endoprothèse. Arch Mal Coeur 1997;90:1307-12.

20 Ellis SG, Tamai H, Nobuyoshi M, et al. Contemporary percutaneous treatment of unprotected left main coronary stenoses. Circulation 1997; 96:3867-72

21 Park SJ, Park SW, Hong MK, et al. Stenting of unprotected left main coronary artery stenoses. J Am Coll Cardiol 1998;31:37-42.

22 Trnka KE, Febres-Roman PR, Cadigan RA, et al. Total occlusion of the left main coronary artery: clinical and catheterization findings. Clin Cardiol 1980;3:352-5.

23 Sciagra R, Tebbe U, Vogt A, et al. Occlusion of the common trunk of the left coronary artery. Physiopathological features and clinical findings. $G$ Ital Cardiol 1986;16:516-21.

24 Farto e Abreu P, Machado FP, Seabra Gomes R. Occlusion of the common branch of the left coronary artery. Clinical and angiographic characteristics and review of the literature. Rev Port Cardiol 1994;13:311-21.

25 Slunga L, Eriksson P, Osterman G. Complete occlusion of the left main coronary artery: clinical and angiographic observations in five cases. Intern Med 1989;225:123-7.

26 Kawasuji $M$, Hetzer R, Oelert $H$, et al. Complete occlusion of the left main coronary artery: report of three surgical cases and review of the literature. Thorac Cardiovasc Surg 1981;29:183-6. 